\title{
Repair costs of reusable bronchoscopes in the intensive care unit
}

\author{
Jonathan S. Kurman^, Bryan S. Benn^ \\ Division of Pulmonary \& Critical Care, Medical College of Wisconsin, Milwaukee, WI, USA \\ Correspondence to: Jonathan S. Kurman, MD, MBA. Assistant Professor of Medicine, Director of Interventional Pulmonology, Division of Pulmonary \\ \& Critical Care, Medical College of Wisconsin, Milwaukee, WI 53226, USA. Email: jkurman@mcw.edu.
}

Submitted Oct 31, 2021. Accepted for publication Jan 30, 2022.

doi: $10.21037 /$ jtd-21-1719

View this article at: https://dx.doi.org/10.21037/jtd-21-1719

\section{Introduction}

Since their introduction in 1968 , reusable flexible bronchoscopes (RFB) have been widely employed in diagnostic and therapeutic bronchoscopic procedures (1). The advent of single-use flexible bronchoscopes (SUFB) poses a challenge to this status quo as they possess several potential advantages. Because they do not need to be reprocessed, SUFB are always sterile, minimizing the risk of cross contamination or infection to both patients and staff (2). With a smaller physical footprint, they can be stored locally at the point of use, facilitating timely access during urgent or emergent situations and after regular hours. While direct comparisons in clinical pulmonology procedures are lacking, SUFB are effective in various anesthesia settings and when performing bronchoalveolar lavage research studies (3-5).

Cost savings are another potential benefit. Economic analyses, however, have been conflicting. Two studies demonstrated that as procedural volume increased, the cost savings of SUFB decreased. Châteauvieux et al. (6) identified 328 cases as the threshold beyond which the cost per case favors reusable bronchoscopes. McCahon et al. (7) calculated an even lower threshold of only 200 cases. Another study found that SUFB were more expensive over a 5-year period, even when used solely for night, weekend, and holiday cases (8).

In contrast, a cost-utility analysis from the United Kingdom showed that SUFB are cost effective compared to RFB with a per case savings of \$290 (9). Similarly, a systematic review determined that SUFB are more costeffective than RFB ( $\$ 300$ per case vs. $\$ 340$ per case) independent of procedural volume (10). Furthermore, they deduced that cost savings become even more pronounced when you factor in the expense of treating iatrogenic infection from instrument contamination.

Regional variation in costs may be a factor. The above studies utilized data primarily from European hospitals. To date, only one study has focused exclusively on institutions in the United States. Ofstead et al. (11) included four hospitals, only one of which was a large center (500 beds). A comprehensive assessment found that the cost per case for RFB and SUFB ranged from \$281-803 and \$220-315, respectively. Because of the overlap at the high-end of the SUFB and at the low-end of the RFB, the authors concluded that "...real-world cost for procedures with reusable bronchoscopes was comparable or higher than the cost of single-use bronchoscopes".

Of the studies referenced, only two reported costs of maintenance and repairs. Châteauvieux et al. (6) calculated an average cost of $\$ 2,524$ per bronchoscope per year. Ofstead et al. (11) included the cost-of-service agreements and out-of-pocket costs in calculating average repair costs of $\$ 3,350$ to $\$ 5,064$ per bronchoscope per year. Over the lifespan of RFB, repair costs may surpass the initial cash outlay, which is significant. Herein, we report the actual repair costs of RFB at our 650-bed tertiary care academic medical center.

\section{Data}

Nine RFB are designated for bedside flexible bronchoscopy procedures in five intensive care units (ICUs). Procedures

^ ORCID: Jonathan S. Kurman, 0000-0001-8018-496X; Bryan S. Benn, 0000-0002-1136-8287. 
Table 1 Age, number of repairs, average repair cost per breakage, range of repair cost, and total repair cost by scope over a 3-year period (May 2018-April 2021)

\begin{tabular}{lcccccc}
\hline Model no. & Type & Age (years) & No. of repairs & Average repair cost & Range of repair cost & Total repair cost \\
\hline Olympus BF-1TH190 & Therapeutic & 7.08 & 6 & $\$ 8,503$ & $\$ 1,859-12,000$ & $\$ 51,019$ \\
Olympus BF-1TH190 & Therapeutic & 5.68 & 5 & $\$ 7,928$ & $\$ 340-12,000$ & $\$ 39,639$ \\
Olympus BF-3C160 & Diagnostic & 9.28 & 2 & $\$ 6,414$ & $\$ 348-12,480$ & $\$ 12,828$ \\
Olympus BF-H190 & Diagnostic & 7.09 & 6 & $\$ 4,779$ & $\$ 340-11,685$ & $\$ 28,671$ \\
Olympus BF-H190 & Diagnostic & 7.08 & 7 & $\$ 7,360$ & $\$ 720-12,000$ & $\$ 51,522$ \\
Olympus BF-H190 & Diagnostic & 5.68 & 3 & $\$ 8,184$ & $\$ 551-12,000$ & $\$ 24,551$ \\
Olympus BF-P190 & Diagnostic & 4.70 & 7 & $\$ 10,287$ & $\$ 324-12,000$ & $\$ 72,009$ \\
Olympus BF-Q180 & Diagnostic & 13.84 & 0 & $\mathrm{~N} / \mathrm{A}$ & $\mathrm{N} / \mathrm{A}$ & $\mathrm{N} / \mathrm{A}$ \\
Olympus BF-Q180 & Diagnostic & 12.97 & 0 & $\mathrm{~N} / \mathrm{A}$ & $\mathrm{N} / \mathrm{A}$ & $\mathrm{N} / \mathrm{A}$ \\
Average & - & 8.16 & 4 & $\$ 7,636$ & $\mathrm{~N} / \mathrm{A}$ & $\$ 40,034$ \\
\hline
\end{tabular}

are performed by providers, including attending physicians and trainees, who staff each unit. The average age of our RFB was 8.16 years (range, $4.70-13.84$ years). During the 3-year period from May 2018 through April 2021, repair costs totaled $\$ 280,239$.

The nine RFB consist of two therapeutic and seven diagnostic scopes (Table 1). The two therapeutic RFB have an average age of 6.38 years and have had repair costs of $\$ 90,658$ total. The second smallest RFB (Olympus BF$\mathrm{P} 190$ ), of which there is only one, had the greatest singlescope repair cost, of $\$ 72,009$. Two of the diagnostic RFB were greater than 12 years old and had no repair costs. This finding likely reflects minimal to no usage, as opposed to impressive durability. Data on the number of times each individual bronchoscope was used are unavailable. During the 3-year period in question, approximately 4,500 flexible bronchoscopies were performed with these RFB. This translates into repair costs of about $\$ 62$ per case.

RFB were sent out for repair 36 times (average 4; range, $2-7)$. The most common reason for repair was "failed leak test" $(50 \%)$. No explanation was provided in $33 \%$ of cases. Which components of the bronchoscope were actually repaired/replaced varied. A "full factory refurbishment" was performed in $54 \%$ of repairs. Excluding the two bronchoscopes with no repair costs, the average repair cost per breakage was $\$ 7,636$, and the average repair cost per scope per year was $\$ 13,344$. Data on the length of time RFB were out of service and on the cost of reprocessing these scopes are unavailable. The opportunity costs of not having a particular scope were unable to be quantified.

\section{Discussion}

The true economic costs of purchasing, maintaining, and repairing RFB are unclear from the literature, with a paucity of data available from the United States. Knowledge of these costs are paramount when assessing the financial viability of transitioning to SUFB. The economic advantages of SUFB are likely more pronounced than originally believed when the real-world costs of RFB, particularly regarding their repair, are entered into the equation. Although the per case cost of repairs (\$62) for RFB is relatively low, the value becomes more substantial when multiplied by the large number of cases performed, especially considering that the alternative option (SUFB) has zero repair costs. Acquisition costs and reprocessing costs of RFB, plus the actual cost of SUFB, are necessary for a truly comprehensive economic comparison between SUFB and RFB, which is beyond the scope of this manuscript.

Analysis of our repair costs show that they are significantly higher than those previously reported $(6,11)$. There are several potential explanations for this phenomenon. First, a limited number of RFB are being utilized (7 of 9), which translates into greater use per scope. Second, RFB are handled by numerous users, including trainees, with varying levels of experience, knowledge, and competence. Third, our procedural volume may exceed that of other centers, thereby increasing "wear and tear" on the equipment. Fourth, the average age of our RFB (8.16 years) is beyond the manufacturer's recommended replacement age of 5 years. Fifth, the vast majority of these cases were 
done via an endotracheal tube, which may have subjected the RFB to increased mechanical stress. Finally, our RFB are housed in a central repository, limiting any sense of ownership or accountability and potentially disincentivizing users to handle the equipment carefully. Together, these factors may account for some of the drastic discrepancy between our real-world repair costs and those previously published (11).

We suspect that our RFB repair costs are likely comparable to those of other large teaching institutions in the United States with similar ICU bronchoscopy setups. In these institutions, the economic advantages of SUFB in the ICU become readily apparent, even before reprocessing costs are factored into the equation. While there will likely always be a role for RFB in more complex cases, SUFB provide an economic advantage without any clear environmental impact (12). We anticipate that this economic benefit will propel SUFB into position as the default device for ICU bronchoscopy cases.

\section{Conclusions}

The recent introduction and rapid advancement in quality of SUFB has set the stage for a paradigm shift in bronchoscopy. While the initial cash outlay for RFB is significant, their ongoing repair costs, particularly at high volume academic medical centers, represent a substantial and previously unrecognized economic burden. The true economic cost of RFB is greater than previously reported and lends further support to the routine use of SUFB for basic bronchoscopy procedures. Multicenter studies evaluating real-world costs of RFB are needed to substantiate our experience.

\section{Acknowledgments}

Funding: None.

\section{Footnote}

Provenance and Peer Review: This article was a standard submission to the journal. The article has undergone external peer review.

Peer Review File: Available at https://jtd.amegroups.com/ article/view/10.21037/jtd-21-1719/prf

Conflicts of Interest: Both authors have completed the ICMJE uniform disclosure form (available at https://jtd.amegroups. com/article/view/10.21037/jtd-21-1719/coif). JSK is a consultant for Boston Scientific and is an advisory board member for Ambu. BSB has no conflicts of interest to declare.

Ethical Statement: The authors are accountable for all aspects of the work in ensuring that questions related to the accuracy or integrity of any part of the work are appropriately investigated and resolved

Open Access Statement: This is an Open Access article distributed in accordance with the Creative Commons Attribution-NonCommercial-NoDerivs 4.0 International License (CC BY-NC-ND 4.0), which permits the noncommercial replication and distribution of the article with the strict proviso that no changes or edits are made and the original work is properly cited (including links to both the formal publication through the relevant DOI and the license). See: https://creativecommons.org/licenses/by-nc-nd/4.0/.

\section{References}

1. Ikeda S, Yanai N, Ishikawa S. Flexible bronchofiberscope. Keio J Med 1968;17:1-16.

2. Ofstead CL, Quick MR, Wetzler HP, et al. Effectiveness of Reprocessing for Flexible Bronchoscopes and Endobronchial Ultrasound Bronchoscopes. Chest 2018;154:1024-34.

3. Barron SP, Kennedy MP. Single-Use (Disposable) Flexible Bronchoscopes: The Future of Bronchoscopy? Adv Ther 2020;37:4538-48.

4. Frerk C, Mitchell VS, McNarry AF, et al. Difficult Airway Society 2015 guidelines for management of unanticipated difficult intubation in adults. Br J Anaesth 2015;115:827-48.

5. Zaidi SR, Collins AM, Mitsi E, et al. Single use and conventional bronchoscopes for Broncho alveolar lavage (BAL) in research: a comparative study (NCT 02515591). BMC Pulm Med 2017;17:83.

6. Châteauvieux C, Farah L, Guérot E, et al. Singleuse flexible bronchoscopes compared with reusable bronchoscopes: Positive organizational impact but a costly solution. J Eval Clin Pract 2018;24:528-35.

7. McCahon RA, Whynes DK. Cost comparison of re-usable and single-use fibrescopes in a large English teaching hospital. Anaesthesia 2015;70:699-706.

8. Videau M, Rghioui K, Mottet B, et al. A comparative 
cost analysis of single-use versus reusable fiberoptic bronchoscopes: Is single-use fiberscope worth it? Ann Pharm Fr 2017;75:473-9.

9. Mærkedahl A, Lindvig A, Pagh A, et al. CostUtility Analysis of the Ambu ${ }^{\circledR}$ aScopeTM 4 Broncho SingleUse Flexible Video Bronchoscope Compared to Reusable Flexible Video Bronchoscopes. J Basic Clin Pharma 2020;11:1-6.

10. Mouritsen JM, Ehlers L, Kovaleva J, et al. A systematic

Cite this article as: Kurman JS, Benn BS. Repair costs of reusable bronchoscopes in the intensive care unit. J Thorac Dis 2022;14(2):591-594. doi: 10.21037/jtd-21-1719 review and cost effectiveness analysis of reusable vs. singleuse flexible bronchoscopes. Anaesthesia 2020;75:529-40.

11. Ofstead CL, Hopkins KM, Eiland JE, et al. Managing bronchoscope quality and cost: Results of a real-world study. Process 2019;62-71.

12. Sørensen BL, Grüttner H. Comparative study on environmental impacts of reusable and single-use bronchoscopes. American Journal of Environmental Protection 2018;7:55-62. 